\title{
Erratum to: Effects of temperature on mortality in Hong Kong: a time series analysis
}

\author{
Wen Yi • Albert P. C. Chan
}

Published online: 15 October 2014

(C) ISB 2014

\section{Erratum to: Int J Biometeorol}

DOI 10.1007/s00484-014-0895-4

In the third sentence of the "Results" section of the original publication, the final phrase "registered in Brisbane" should have read "registered in Hong Kong."

The online version of the original article can be found at http://dx.doi.org/ 10.1007/s00484-014-0895-4.

W. Yi $(\square) \cdot$ A. P. C. Chan

Department of Building and Real Estate, Faculty of Construction and

Environment, The Hong Kong Polytechnic University, 11 Yuk Choi

Road, Hung Hom, Kowloon, Hong Kong, China

e-mail: yiwen96@163.com 